East African Medical Journal Vol. 86 No. 2 February 2009

GENDER DIFFERENCES IN THE HOUSEHOLD-HEADSHIP AND NUTRITIONAL STATUS OF PRE-SCHOOL CHILDREN

J. Haidar, MD, MSc., Associate Professor, School of Public Health, Addis Ababa University, P. O. Box 27285-1000, Addis Ababa, Ethiopia and W. Kogi-Makau, PhD, Associate Professor, Applied Human Nutrition Programme, University of Nairobi, P. O. Box 29053-00625, Uthiru, Nairobi, Kenya

Request for reprints to: Dr. J. Haidar, Ethiopian Health and Nutrition Research Institute, Ethiopia, P. O. Box 27285-1000, Addis Ababa, Ethiopia

\title{
GENDER DIFFERENCES IN THE HOUSEHOLD-HEADSHIP AND NUTRITIONAL STATUS OF PRE-SCHOOL CHILDREN
}

\author{
J. HAIDAR and W. KOGI-MAKAU
}

\begin{abstract}
Background: In genera self declared female headed-households in most developing countries tend to be poorer, own less and have less access to job opportunities.

Objective: To assess the nutritional status of pre-schoolers by gender differentiation of heads of households.

Design: A cross-sectional descriptive study carried out in February 2003.

Setting: Four beneficiary villages registered under the Ethio-Danish joint community development programme in North Ethiopia.

Subjects: A total of 144 heads of random systematically selected households regrouped as male-headed $(n=96)$ and female-headed households $(n=48)$ with their respective preschoolers.

Main outcome measures: Nutritional status of two groups of children categorised by gender of the head of household.

Results: The number of pre-schoolers from male-headed households was 1.54 as opposed to the female-headed households (1.08). The proportion of stunted and underweight pre-schoolers was significantly higher in female headed-households than in the male-headed households while the prevalence of wasting was practically similar. The proportion of vaccinated and breastfed children, although not statistically significant, was higher in male headed households while the practice of colostrums feeding, giving water and butter, vitamin A and appropriate weaning was better in female headed households. The difference noted in prevalence of feeding colostrums was significant. The energy, protein and vitamin A intake in almost all of the households was below the recommended daily allowances; showing a nutrient adequacy ratio of $50.2 \%, 48.8 \%$ and $17.9 \%$ respectively whereas iron intake exceeded $100 \%$. The energy, protein, vitamin $\mathrm{A}$ and iron intake was better in the male-headed households than in female-headed households. The difference, however, was statistically significant for energy only.

Conclusion: This study delineated that chronic child under-nutrition is not only higher among female children but also in female headed households and hence the implication of gender biased violation of the right to nutrition security. Other important implication of this study is that apart from gender issues alternative livelihood options that promote healthy behaviours, such as, improving the provision of health services and curbing the harmful traditional practices that may have a dual impact on the well being of mothers and children is recommended.
\end{abstract}

\section{INTRODUCTION}

Less than twenty per cent of eastern and South African households have access to adequate food supplies. When faced with such shortcomings and with underlying chronic diseases, children are prone to develop protein energy malnutrition and other multi-nutrient deficiency disorders (1). Other factors contributing to the development of above problems are early weaning, late birth order and gender bias, usually against females, among others which suggest an unequal distribution of available nutrition resources at household level $(2,3)$. The relationship between malnutrition and human behaviour is very important where nutritional problem in children is common $(4,5)$. To date, several studies have covered 
varied areas of risk factors that contribute to child malnutrition (6-9). Recently published work in the area indicate, that a wide range of socioeconomic, demographic, environmental, cultural barriers, including maternal attributes influence the nutritional status of preschool children (8).

Acomparative analysis madeby the International Food Research Policy Institute (IFPRI) in two African countries namely Kenya and Ghana, revealed that female headed-households (FHH) have a larger dependency ratio than male headed households $(\mathrm{MHH})$ suggesting that the differences noted were related to gender variation to some extent (10). It has recently been demonstrated that self declared female headed-households tend to be poorer, own less and have less access tojob opportunities and government services in most developing countries. This is definitely a concern for policy makers since FHH are on the increase and it appears to pose challenges in designing policies to improve the maternal health and child nutrition in most developing countries (11). Although evidence on differences in socio-economic measure across gender based household headship types is becoming more widespread. Still more work is necessary to fill the gap in the different countries contexts. The aim of this study was therefore; to assess the level of preschoolers' nutritional status across household groupings that are differentiated by gender household headship and provide policy makers with evidence based information for planning and appropriate intervention.

\section{MATERIALS AND METHODS}

A cross-sectional descriptive study was conducted during February 2003 in four beneficiary rural villages registered under the Ethio-Danish joint community development programme in North Ethiopia as part of impact assessment on the programme on various socioeconomic and nutritional variables. All the four villages are well known for repeated history of drought, poor basic social services and food insecurity for which an integrated rural development programmein health / nutritioneducation, agriculture and gender equity were initiated.

A list of households with preschool children (PSC) aged 6-59 months was obtained to form the sampling frame. From the list, a systematic sample of 36 households from each village regrouped as femaleheaded households (FHH) where households in which a woman was thelegal head, and a self declared male-head absent for $50 \%$ of time from the residence while male-headed households (MHH) where the male was the legal and customary head and always present for $50 \%$ of time in his residence. A total of 144 beneficiary households-head composed of $48 \mathrm{FHH}$ with 52 preschoolers and $96 \mathrm{MHH}$ with 148 PSC was obtained and assessed for various socio-demographic, nutritional status and child characteristics.

Socio-demographic and child information was collected by trained field workers from the villages using pre-tested questionnaire. Weights of children were measured to the nearest $0.1 \mathrm{~kg}$ with a portable beam balance calibrated at regular interval. Height measurements were taken using a wooden board to the nearest centimetre for those who could stand while length board was used for children below the age of two years; height for age (HAZ), weight for height (WASZ) and weight for height (WHZ) z-scores respectively were derived by using national centre for health statistics (NCHS) reference standards $(12,13)$ for determining nutritional status of children. The results were classified as stunting, underweight and wasting if they had a z-score of below minus two for HAZ, WAZ and WHZ respectively. Data was entered and analysed using statistical package for social science (SPSS) version 10 and ANTHRO software.

A 24-hour dietary recall was conducted that yielded intake estimates for energy, protein, vitamin A and iron of the study children. The child caregivers at the household level were requested to identify by name all the meals that the index child had eaten in the previous 24 hours and subsequently estimate (in form of volumes), each food item that constituted the dishes and the portion consumed using household utensils. These were then converted into nutrient estimates using food tables (14).

\section{RESULTS}

In the present study, households were disaggregated on the basis of gender of the household head and the time spent away from the residence by the self declared male heads of households; to get a clear picture of the parent most responsible for a child's nutritional status. Of the total 200 preschool children assessed, 52 of them were from the female-headed households and 148 from male-headed households. The number of preschool children supported by male-headed households and a female-headed household was 1.54 and 1.08 respectively indicating that the male-headed households have higher child dependency ratios.

Figure 1 depicts the nutritional status of children by gender of the household head. The proportion of stunted and underweight preschoolers was significantly higher among female-headed households than the male-headed households whereas the prevalence of wasting was practically similar. 
Figure 1

Preschoolers' nutritional status by household headship

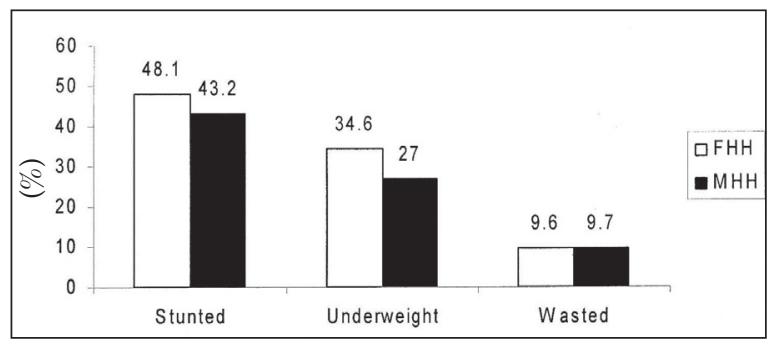

The distribution of selected child characteristics by household's headship is displayed in Table 1. The proportion of vaccinated and breast feeding children was higher in male-headed households but not statistically significant from that of FHH. The practice of feeding colostrums, water and butter, appropriate weaning, taking mega dose of vitamin $\mathrm{A}$ was more prevalent in female-headed households but the differences were only significant for colostrums feeding.

Table 1

Distribution in percentage of selected index child characteristics by household's headship

\begin{tabular}{crrrr}
\hline Variable & $\begin{array}{r}\mathrm{FHH} \\
(\mathrm{n}=48)\end{array}$ & $\begin{array}{c}\text { MHH } \\
(\mathrm{n}=96)\end{array}$ & X-value & P-value \\
\hline Vaccinated & & & & \\
Yes & 86.3 & 91.0 & & \\
No & 13.6 & 9.0 & 0.43 & 0.5
\end{tabular}

Breast fed

$\begin{array}{rrrrr}\text { Yes } & 90.9 & 97.0 & & \\ \text { No } & 9.1 & 3.0 & 0.92 & 0.3\end{array}$

Colostrums fed

$\begin{array}{lllll}\text { Yes } & 81.3 & 75.3 & & \\ \text { No } & 18.7 & 24.7 & 24.3 & 0.0\end{array}$

Child fed on butter

$\begin{array}{lllll}\text { Yes } & 68.2 & 66.3 & & \\ \text { No } & 31.8 & 33.3 & 0.00 & 0.9\end{array}$

Child fed on water

$\begin{array}{lllll}\text { Yes } & 19.0 & 14.7 & & \\ \text { No } & 81.0 & 85.3 & 0.16 & 0.6\end{array}$

Weaning food given

$\begin{array}{rrrrr}\text { Yes } & 90.9 & 83.8 & & \\ \text { No } & 9.1 & 16.2 & 1.23 & 0.2\end{array}$

Vitamin A given

\begin{tabular}{rrrrr} 
Yes & 90.9 & 83.8 & & \\
No & 9.1 & 16.2 & 1.23 & 0.2 \\
\hline
\end{tabular}

FHH=Female Headed Households; $\mathrm{MHH}=$ Male Headed Households; figures in parenthesis are percentages
The energy intake in almost all of the households was below the recommended daily allowances indicating a nutrient adequacy ratio of 50.2\% (Table 2). Likewise, protein and vitamin A intake were also low demonstrating a nutrient adequacy ratio of $48.8 \%$ and $17.9 \%$ for protein and vitamin A respectively whereas iron intake exceeded $100 \%$. The energy, protein, vitamin A and iron intake was better in the male-headed households when compared with the female-headed households. The difference noted however, was significant for energy but not for the other nutrients.

Table 2

Nutrient and energy intake per capita by household'sheadship

\begin{tabular}{lcccc}
\hline Variable & FHH & MHH & SE & $95 \% \mathrm{CI}$ \\
\hline Energy (kcal) & 1164 & 1302 & 9.5 & $19.3-56.7^{*}$ \\
Protein (gm) & 32 & 38 & 0.9 & $4.1-7.8$ \\
Vitamin A (mcg) & 132 & 139 & 1.9 & $3.2-10.7$ \\
Iron (mg) & 61.4 & 71 & 2.9 & $3.7-15.5$ \\
\hline
\end{tabular}

* $=\mathrm{P}<0.05 ; \mathrm{FHH}=$ Female Headed Household; $\mathrm{MHH}=$ Male Headed Households

\section{DISCUSSION}

Information on the socio-demographic attributes gender based headship is important in the exploration of their interaction with malnutrition in the different countries contexts. To date, studies' addressing the issue of gender headship seems to attract researchers and policy makers as female household headship is increasing and appears to pose challenges in designing policies to improve maternal health and child nutrition in most developing countries (11). Furthermore, self declared femaleheaded-households tend to be poorer, own less and have less access to job opportunities and government services in most developing countries.

On the basis of the analysis made by the International Food Research Policy Institute in two African countries; namely Kenya and Ghana, female headed-households are noted to have a larger dependency ratio than male-headed households suggesting that to some extent the differences were related to gender variation. Interestingly, this was not seen in the present analysis, as it is the MHH that had higher child dependency ratio when compared with the FHH. Probably the female heads had authority in deciding the number of children to have by possibly having translated their knowledgein family planning into practice. The findings in this study are important because they bring out human rights perspective in nutritional deprivation and hence offer alternative 
means of perceiving and hopefully dealing with the health and nutritional problem in the country as well as in Africa. One important implication of the findings of this study is that apart from gender issues other livelihood options that promote healthy behaviours like improving provision of health services may have a dual impact on the well being of mothers and children.

Although both sets of households were equally exposed to poverty, as reflected in the heavy reliance on food aid, the disparities noted in the level of chronic malnutrition in the preschoolers are particularly noticeable among $\mathrm{FHH}$ indicating that children from such households are likely to be more vulnerable to malnutrition. Besides, widely applied harmful traditional practices, such as feeding butter and water to children in this kind of typical rural area where the hygiene level of domestic and peridomestic environments are poor, definitely entail risk of contamination which lead to various kinds of communicable diseases and malnutrition among children. Therefore, both sets of households should be discouraged from such harmful habits particularly consumption of butter due to its negative health consequences and in its place encourage the positive habits of colostrums and breast feedings to newborn babies.

In general, the dietary nutrient intake in almost all of the households, with the exception of iron, was below the recommended daily allowances. Such a low intake pattern is typical for many of the developing African countries. This might be the major reason for the manifestation of chronic energy deficiency by a large segment of the population. The low energy intake found in the present study is similar to earlier findings reported in the country $(15-18)$. When dietary intake was disaggregated by household type, the nutrient intake in male headedhouseholds was relatively better than the femaleheaded groups; the difference however, was not statistically significant. Usually such manifestations are common as male-headed households have the advantages of being involved in various income generating activities away from their homestead that probably affords them better opportunities to access better food consumption. The inequalities in health and nutrition across the families are pervasive and seem to be unfair because they correspond to different constraints and opportunities rather than individual choice. To curb the inequities it is imperative to devise strategies that focus on women with the aim of making basic health services affordable and hence more widely available and accessible to poor urban and rural people.

Many studies report the impact of behaviour of duty-bears at the household level on child nutrition but fail to extend interpretation of the findings into a human rights frame yet the importance of analysing differences within households and communities to avoid unintentional discrimination against particular groups of people (19) is being increasingly acknowledged. Interpretation of the findings of this study thus bring to the fore human rights perspective as an innovative way of viewing nutritional challenges and deprivation that is in keeping with the application to the in vogue human rights approach to programming. Human rights approaches focus on accountability and identification of duty-bearers (those responsible for realisation of rights) (20). Often nutrition studies fail to make explicit pertinence of rights in the existing child nutrition-influencing environment as well as in seeking solution to the nutritional challenges such as those highlighted by this study.

It is universally accepted that adequate food and nutrition security is a right for all and should, therefore, be respected and fulfilled without discrimination of any kind. The findings of this study indicate gender tilted violation of fulfilment of the right to nutrition security of the female children at the household level that manifests as impact of chronic (long-term) rather than acute deprivation; which implies that the female child with or without the intention of duty-bearer has been perpetually subtly subjected to under-feeding when compared to the male child.

As established by this study, wasting, which is a reflection of impact of acute nutritional deprivation, thus impact of short-term violation of the right to adequate food and health and as such to nutrition security influences nutritional status of both female and male children in a gender unbiased way. Nevertheless, stunting and underweight levels reflect gender discrimination thus rights violation to the disadvantage of the female child. The findings further indicate that gender bias is not limited to females in their early life but it follows them to the older ages thus the children in FHH (parents being secondary rights claimant for their children) had significantly lower energy intake when compared with those in $\mathrm{MHH}$. This also moves the level of responsibility from the household to higher levels that are responsible for structures that are discriminative against females.

This study delineated that chronic child undernutrition is not only higher among female children but also in female headed households and hence the implication of existence of gender biased violation of the right to nutrition security. This type of violation must be seen and interpreted in a framework clearly expressed by Johnson in this citation "If a right is a claim, then those against whom the claim can be made (duty bearers) must be made accountable for the realisation of that right" (20).

To ensure that basic health services are reaching the poor and rural people, a new innovation, known 
as Health Service Extension Programme, has been integrated in the health sector development in Ethiopia. This commendable effort is seen as a way forward as it is providing services at village and household levels with focus on sustained preventive health actions and increased health awareness. It is considered to be an important institutional framework for achieving millennium development goals because of its capacity to shift health care resources to populous rural areas (21).

\section{ACKNOWLEDGEMENTS}

The financial support rendered by the joint EthioDanish Programme is highly acknowledged.

\section{REFERENCES}

1. Mwadime, R.K.N. and Baldwin, S.L. Relationship between household access to food and malnutrition in Eastern and Southern Africa. East Afr. Med J. 1994; 71: 571-579.

2. Muhuri,P.K. and PrestonS.H.Mortality differentials by sex in Bangladesh. Pop. Dev. Rev. 1991; 17: 415-434.

3. Caldwell P. Child survival: Physical vulnerability and resilience in adversity in European past and the contemporary third world. Soc. Med. Sci. 1996; 45: 609-619.

4. Josef, B. and Beat, S. Consequence of malnutrition: Malnutrition and programs behaviour. Abstracts about food and nutrition policy, planning and MS. School of Tufts Univ. 1987; 7: 12-19.

5. Pal Mwadineojoki P. The relationship between nutrition knowledge and food behavior among finish home markers. J. Consum. Stud. Home Econ. 1996; 20:327-338.

6. Pinstrup-Anerson, P., Burger, S., Habicht, J.P. and Peterson, K. Protein-energy malnutrition. In Jamison D.T, Mosley W.H, Meashan A, Bobadilla J.L, eds. Disease control priorities in developing countries. New York: Oxford University Press for the World Bank. 1993:391-420.

7. Leslie, J. and Jamison, D.T. Health and nutrition consideration in education planning. Educational consequences of health problems among school-age children. Food. Nutr. Bull. 1990: 12: 191-103.

8. Haidar, J., Abate, G., Kogi-Makau, W. and Sorensen P. Risk factors for child under-nutrition with a human rights edge in rural villages of North W ollo, Ethiopia. East Afr. Med. J. 2005; 82: 625-630.
9. Umeta, M., West, C., Hans, V. and Jemal, H. Factors associated with stunting in infants aged 5-11 months in the Dodota-Sire District. Rural Ethiopia. J. Nutr. 2003; 133: 1064-1069.

10. Kennedy E. and Haddad L. Are preschoolers from female-headed households less malnourished? A comparative analysis of results from Kenya and Ghana. Intern. Food Policy Res. Institute Bull. 1994; 291: 681-695.

11. Gupta, G. Female-headed households, poverty and child welfare. Paper presented at the population council/ ICRW seminar series on determinants and consequences of female-headed households. 1989.

12. WHO working group. Use and interpretation of anthropometric indicators of nutritional status. Bull. Wld. Hlth. Org. 1986; 64: 929-941.

13. Hamil, P.V., Drizd, T. A., Johnson, C. L., et al. Physical growth: National centre for health statistics percentiles. Am. J. Clin. Nutr. 1979; 32: 607-629.

14. West, C.E. and vanStaveren, W.A. Food consumption, nutrient intake and use of food composition tables. In: Design concepts in nutritional epidemiology. Editors. B.M. Margetts and M. Nelson. Oxford University Press, Oxford. 1991; 101-119.

15. Gibson, R.S. Principle of Nutritional Assessment. New York, Oxford University Press, 1990.

16. Jemal, H., Shapiro, B., Demissie, T. and Gebrewold, A. Thenutritional and health status of women and children in households with and without crosbred cows Holetta wereda, Ethiopia. In: Jabar M, Peden A, Mohamed S. etal.eds.Agro-ecosystem, natural resourcemanagement and human health related research in East Africa. ILRI, Addis Ababa, 1992; 124-136.

17. Demissie, T., Yared, M. and Jemal, H. Agroecological comparisons of levels and correlates of maternal malnutrition in Hadiya zone, SNNPR. Ethiop. J. Health Dev. 2003; 17: 189-196.

18. WoldeGabriel, Z., Workineh, A. and Teferra, G. Formative study on socioeconomic and nutritional status of mothers and children. Farm Afric Dairy Goat Development Project Addis Ababa, 1997.

19. Gosling, J. and Edwards, M. Chapter 3- Recognising and dealing with differences and discrimination. In: Toolkits. A practical guide to planning, monitoring, evaluation and impact monitoring. Second Edition. Save the Children, Warwickshire. 2003 :26-27.

20. Jonsson, U.Human rights and concepts and principles. In: Human rights approach to development programming. UNICEF, Nairobi. 2003: 20.

21. Ministry of Health(MOH). Health sector development program II 2002/ 03-2004/ 05, June 2002, Ethiopia. 